\title{
Absorbed power distribution in the whole-body system of a tractor operator
}

\author{
Jacek Kromulski', Tadeusz Pawłowski', Jan Szczepaniak', Wojciech Tanaś' ${ }^{2}$, Andrzej Wojtyła ${ }^{3}$, \\ Mariusz Szymanek ${ }^{2}$, Jacek Tanaśs ${ }^{4}$, Waldemar Izdebski ${ }^{5}$ \\ ${ }^{1}$ Industrial Institute of Agricultural Engineering, Poznań, Poland \\ ${ }^{2}$ University of Life Sciences, Lublin, Poland \\ ${ }^{3}$ Department of Health Sciences, University of Medical Sciences, Poznań, Poland \\ ${ }^{4}$ University of Technology, Lublin, Poland \\ ${ }^{5}$ Warsaw University of Technology, Poland
}

Kromulski J, Pawłowski T, Szczepaniak J, Tanaś W, Wojtyła A, Szymanek M, Tanaś J, Izdebski W. Absorbed power distribution in the wholebody system of a tractor operator. Ann Agric Environ Med. 2016; 23(2): 373-376. doi: 10.5604/12321966.1203908

\begin{abstract}
Introduction and objective. Many people are exposed to vibration (WBV) in their occupational lives. The biodynamic responses of the human body in sitting conditions have been widely measured under whole-body vibration (WBV). The measures are most often expressed in terms of force-motion relations at the driving-point, namely, mechanical impedance, apparent mass and absorbed power, and flow of vibration through the body, such as seat-to-head and body segments vibration transmissibility. The absorbed power is a measure of the energy absorbed by the subject due to the external forces applied to the system.

Materials and methods. The body behaves like a vibrating physical system with distributed energy-storage elements (masses, springs) and energy-dissipation elements (dampers). The total quantity of power can be divided into 2 components one real and one imaginary. The real component reflects the energy-absorbing part of the system, due to the transformation of friction into heat within the tissues. The imaginary component reflects the energy-storing part of the system which does not consume any vibration energy.

Results. The seated human is modeled as a series 4-DOF dynamic models. After introduction of the excitation, the response in particular segments of the model can be analyzed. As an example, the vibration power dissipated in an operator's body segments has been determined as a function of the agricultural combination operating speed $1.4-2.75 \mathrm{~ms}^{-1}$.

Conclusions. The concept of absorbed power as a measurement for evaluation of WBV exposure opens a new area for research. The important character of absorbed power is that it has physical significance and therefore can be measured as well as computed analytically.

The absorbed power relates to dissipation of energy attributed to relative motions of the visco-elastic tissues, muscles and skeletal system, which under prolonged exposures could lead to physical damage in the musculoskeletal system. A structural model of the human operator allows determination of the dynamic characteristics of the model, and study of the energy flow between the elements of the model.
\end{abstract}

Key words

vibration, whole body, human body model, power, absorption

\section{INTRODUCTION}

The human body is a very sophisticated dynamic system. Plenty of mathematical models have been developed to describe the biodynamic responses of human beings [1] According to different modeling techniques, these models can be grouped as lumped-parameter models, finite element (FE) models, and multibody models. Lumped-parameter models consider the human body as several concentrated masses (rigid bodies) interconnected by springs and dampers. This type of model is simple to analyze and easy to validate with experiments [2]. The main difference between the lumped-parameter human body models refers to the number of degrees of freedom (DOF).

Address for correspondence: Wojciech Tanaś, University of Life Sciences in Lublin 20-612 Lublin, ul. Głęboka 28, Poland

E-mail:wojciech.tanas@up.lublin.pl

Received: 16 April 2014; accepted: 29 October 2014

\section{OBJECTIVES}

The subjective experience of vibration is related to the amount of vibration energy absorbed by the body. The body behaves like a vibrating physical system with distributed energystorage elements (masses, springs) and energy-dissipation elements (dampers). The prevalence of vibration-induced injuries within different occupational groups is related to the amount of absorbed energy. The important characteristic of absorbed power is that it has physical significance, and therefore can be measured as well as computed analytically. Power is a scalar quantity and can be summed-up in complex multi-degree of freedom systems to determine the human response. A structural model of a human operator allows determination of the dynamic characteristics of the model, and study of the energy flow between the elements of the model. 


\section{MATERIALS AND METHODS}

Biomechanical modeling. In 1981, one of the first models, a parallel 2-DOF model for both sitting and standing position, was presented by the International Organization for Standardization (ISO 5982) [3]. In 1995, Wan and Schimmels developed a series/parallel 4-DOF human dynamic. Muksian and Nash proposed 6- and 2-DOF models, respectively, to study the biodynamic responses of seated human bodies. Patil and Palanichamy suggested a 7-DOF model by adding another set of springs and dampers into Muskian's 6-DOF model $[4,5,6,7]$.

In the presented study, a series 4-DOF models have been used, in which the seated human body was constructed with 4 separate mass segments interconnected by 4 sets of springs and dampers, with a total human mass of $76 \mathrm{~kg}$. The masses represent the following body segments: head and neck $\left(\mathrm{m}_{1}\right)$, upper torso $\left(\mathrm{m}_{2}\right)$, lower torso $\left(\mathrm{m}_{3}\right)$, and thighs and pelvis $\left(\mathrm{m}_{4}\right)$. The arms and legs are combined with the upper torso and thigh, respectively. The stiffness and damping properties of thighs and pelvis are $\left(\mathrm{k}_{4}\right)$ and $\left(\mathrm{c}_{4}\right)$, the lower torso $\left(\mathrm{k}_{3}\right)$ and $\left(\mathrm{c}_{3}\right)$, upper torso $\left(\mathrm{k}_{2}\right)$ and $\left(\mathrm{c}_{2}\right)$, and head $\left(\mathrm{k}_{1}\right)$ and $\left(\mathrm{c}_{1}\right)$.

Physical parameters of the biodynamic model were calculated on the basis of the power spectral densities (PSD) quotients of mechanical vibration acceleration measured at the points of freedom of the system.

The schematic of the model is shown in Figure 1, and biomechanical parameters of the model listed in Table 1.

Table 1. Parameter values of the identified 4-DOF

\begin{tabular}{lcc}
\hline \multicolumn{3}{c}{ Biomechanical parameters } \\
\hline Mass $(\mathrm{kg})$ & Damping $\left(\mathrm{kgs}^{-1}\right)$ & Stiffness $\left(\mathrm{Nm}^{-1}\right)$ \\
\hline head $\mathrm{m}_{1}=5,5$ & $\mathrm{c}_{1}=94.8$ & $\mathrm{k}_{1}=5909$ \\
upper torso $\mathrm{m}_{2}=40,3$ & $\mathrm{c}_{2}=232,4$ & $\mathrm{k}_{2}=309570$ \\
lower torso $\mathrm{m}_{3}=12,2$ & $\mathrm{c}_{3}=1920$ & $\mathrm{k}_{3}=17219$ \\
pelvis $\mathrm{m}_{4}=18$ & $\mathrm{c}_{4}=500$ & $\mathrm{k}_{4}=21667$ \\
\hline
\end{tabular}

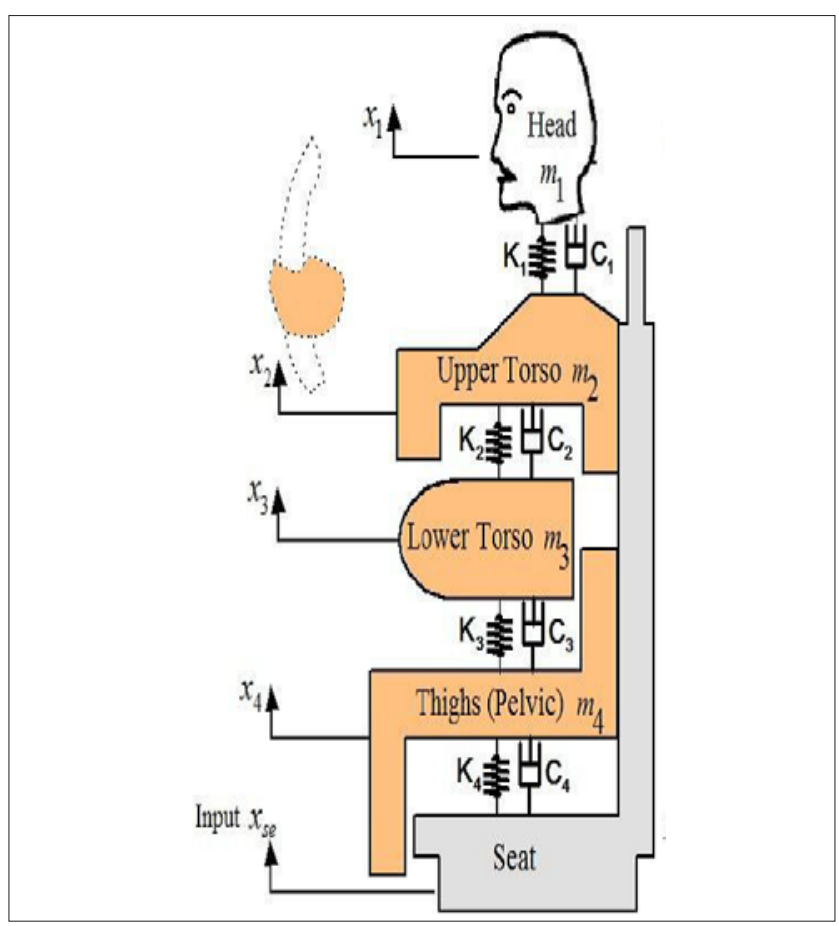

Figure 1. Schematic diagram of 4-DOF seated human model $[4,5]$
Estimation of biodynamic response characteristics. The equations of motion for the analyzed 4-DOF model is determined by applying Newton's Second Law to a free body diagram of each mass. The result is an equation of motion for each degree of freedom (1):

$$
\begin{gathered}
m_{1} \ddot{x}_{1}+c_{1} \dot{x}_{1}-c_{1} \dot{x}_{2}+k_{1} x_{1}-k_{1} x_{2}=0 \\
m_{2} \ddot{x}_{2}+\dot{x}_{2}\left(c_{1}+c_{2}\right)+x_{2}\left(k_{1}+k_{2}\right)-c_{1} \dot{x}_{1}-c_{2} \dot{x}_{3}-k_{1} x_{1}-k_{2} x_{3}=0 \\
m_{3} \ddot{x}_{3}+\dot{x}_{3}\left(c_{2}+c_{3}\right)+x_{3}\left(k_{2}+k_{3}\right)-c_{2} \dot{x}_{2}-c_{3} \dot{x}_{4}-k_{2} x_{2}-k_{3} x_{4}=0 \\
m_{4} \ddot{x}_{4}+\dot{x}_{4}\left(c_{3}+c_{4}\right)+x_{4}\left(k_{3}+k_{4}\right)+k_{3} x_{3}-c_{3} \dot{x}_{3}=c_{4} \dot{x}_{s e}+k_{4} x_{s e}
\end{gathered}
$$

written in matrix form as (2):

$$
[M\}\{\ddot{x}\}+[C]\{\dot{x}\}+[K]\{x\}=\{f\}
$$

where $[M],[C]$ and $[K]$ denote the mass, damping and stiffness matrices,

$$
\begin{gathered}
M=\left[\begin{array}{cccc}
m_{1} & 0 & 0 & 0 \\
0 & m_{2} & 0 & 0 \\
0 & 0 & m_{3} & 0 \\
0 & 0 & 0 & m_{4}
\end{array}\right] ; K=\left[\begin{array}{cccc}
k_{1} & -k_{1} & 0 & 0 \\
-k_{1} & k_{1}+k_{2} & -k_{2} & 0 \\
0 & -k_{2} & k_{2}+k_{3} & -k_{3} \\
0 & 0 & -k_{3} & k_{3}+k_{4}
\end{array}\right] \\
C=\left[\begin{array}{cccc}
c_{1} & -c_{1} & 0 & 0 \\
-c_{1} & c_{1}+c_{2} & -c_{2} & 0 \\
0 & -c_{2} & c_{2}+c_{3} & -c_{3} \\
0 & 0 & -c_{3} & c_{3}+c_{4}
\end{array}\right]
\end{gathered}
$$

$\{f\},\{\dot{x}\},\{\ddot{x}\}$ and $\{x\}$ are the force, displacement, velocity and acceleration vectors, respectively. For the presented 4-DOF model the force vector is given as $[4,8]$ :

$$
\{f\}=\left\{0,0,0, c_{4} \dot{x}_{s e}+k_{4} x_{s e}\right\}
$$

This set of equations represents the dynamic characteristics of the system in terms of mass, stiffness, and damping. Each matrix is square and symmetric with size equal to the number of degrees of freedom of the system.

Identification of vibration energy absorbed in the biodynamical model. The measurement of absorbed power can be performed either in the time or in the frequency domain:

- in the time domain, it requires the simultaneous measurement of force and velocity at any given instant of time;

- in the frequency domain, absorbed power is calculated as the real part of the complex cross-spectrum of force and velocity.

The instantaneous power $\left(\mathrm{P}_{\mathrm{Tr}}\right)$ transmitted to the human body during vibration can be calculated from the product of the force (F) and velocity (v) measured at the interface between the body and the vibrating surface $[9,10,11]$.

$$
P_{T r}=F(t) v(t)=P_{A b s}(t)+P_{E l}(t)
$$

$\mathrm{P}_{\mathrm{Abs}}(\mathrm{t})$ is the absorbed part of the power, accounting for the energy necessary for keeping pace with the energy dissipated through structural damping The elastic power $\mathrm{P}_{\mathrm{El}}(\mathrm{t})$ is continuously delivered to and removed from the body 
during each period of excitation, and averages to zero for each sinusoidal cycle of motion. Thus, the time-averaged absorbed power $<\mathrm{P}_{\mathrm{Abs}}>$ equals the transmitted power $<\mathrm{P}_{\mathrm{Tr}}>$, i.e.,

$$
\left\langle P_{A b s}\right\rangle=\left\langle P_{T r}\right\rangle=\langle F(t) v(t)\rangle
$$

The power transmitted to the body can be calculated in the frequency domain from the cross-spectrum between the force and the velocity. The real part of the transmitted power represents the power absorbed by the body $[12,13,14]$ :

$$
\left.P_{A b s}=\operatorname{Re}\left(G_{v F}(f)\right)\right)
$$

where Re is real part and $\mathrm{G}_{\mathrm{vF}}$ is the cross-spectrum of velocity and force signals, and $\mathrm{f}$ is the frequency. Acceleration signals (a) are generally used instead of velocity (v) for practical measurements. By inserting the relationship $\mathrm{v}=\mathrm{a} / \mathrm{j} \omega$, and using, total active power injected through a point junction by a point force is obtained as:

$$
P_{A b s}=\frac{1}{\omega} \operatorname{Im}\left(G_{F a}\right)
$$

where $G_{\mathrm{Fa}}$ is the cross-spectrum of force and acceleration signals, Im is the imaginary part, and $\omega=2 \pi \mathrm{f}$ is the angular frequency. By adding the value of $\omega$, it is possible to obtain an input power equation in terms of frequency (f):

$$
P_{A b s}=\frac{0.159}{f} \operatorname{Im}\left(G_{F a}\right)
$$

\section{RESULTS}

In order to study the energy content of the vibration transmitted to the whole body and to different body segments, a 4-DOF linear biodynamic model was chosen to represent the body. The local absorbed power and total power absorption under different excitations (different operating speed) are obtained.

Identification of vibration energy absorbed by the body during the work of the aggregate at various working speeds. The data used for identification of absorbed power was collected from a series experiments in the field, in a typical operational condition driving scenario (Fig. 2). An agricultural combination tractor-mower were operated at a different operating speed $1.4 \div 2.75 \mathrm{~ms}^{-1}$.

Whole body vibration (WBV) exposures were calculated per ISO 2631-1 (1997) [15]. According to ISO 2631-1, the weighted value of acceleration $\left(\mathrm{a}_{\mathrm{w}}\right)$ can be used to evaluate human riding comfort.

Table 2. Vector-sum (root-sum-of-squares) vibration magnitude, the r.m.s. acceleration in operator's seat during work of the aggregate at various working speeds

\begin{tabular}{cccc}
\hline No. & $\begin{array}{c}\text { Agricultural } \\
\text { combination }\end{array}$ & $\begin{array}{c}\text { weighted value of } \\
\text { acceleration in vertical }\end{array}$ & $\begin{array}{c}\text { Vector sum of weighted } \\
\text { values of acceleration in }\end{array}$ \\
\hline speed $\left[\mathrm{ms}^{-1}\right]$ & direction $\left(\mathrm{a}_{\mathrm{w}}\right)_{\mathrm{z}}$ & direction ' $\mathrm{x}^{\prime}, \mathrm{y}^{\prime} \mathrm{y}^{\prime} \mathrm{z}^{\prime}\left(\mathrm{a}_{\mathrm{w}}\right)_{\text {wek }}$ \\
\hline 2 & 1.40 & 0.60 & 1.53 \\
\hline 3 & 2.15 & 0.74 & 1.79 \\
\hline
\end{tabular}

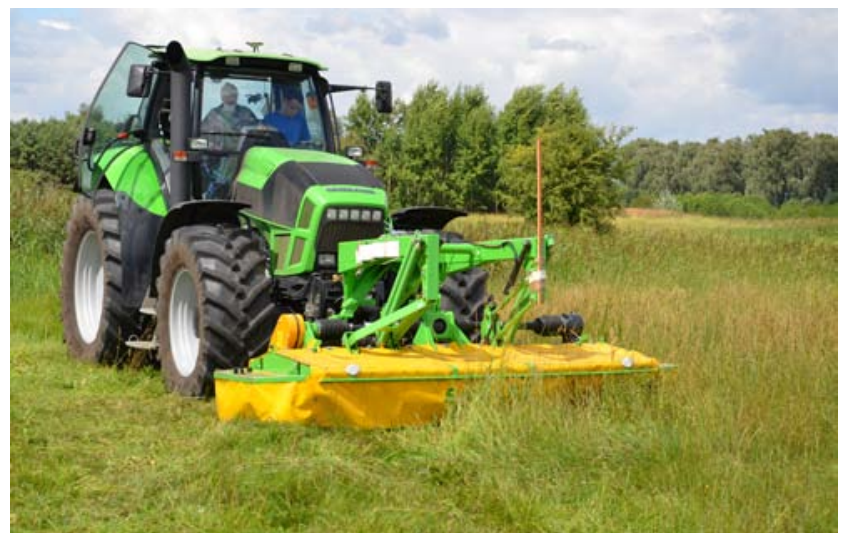

Figure 2. Tractor-mower set during field tests. Instantaneous absorbed powers for different body segments were computed from [11, 16]

$$
P_{A b s, i}(t)=c_{i}\left(\dot{x}_{i}-\dot{x}_{i+1}\right)^{2}
$$

total instantaneous absorbed power is given by:

$$
P_{T o t}(t)=\sum_{i=1}^{4} c_{i}\left(\dot{x}_{i}-\dot{x}_{i+1}\right)^{2}
$$

\begin{tabular}{|c|c|c|c|c|}
\hline \multirow[t]{2}{*}{ No. } & \multirow{2}{*}{$\begin{array}{l}\text { Absorbed power in body segments } \\
{[\text { W] }}\end{array}$} & \multicolumn{3}{|c|}{$\begin{array}{l}\text { Tractor mower set speed } \\
\qquad\left[\mathrm{ms}^{-1}\right]\end{array}$} \\
\hline & & $1.40 \mathrm{~ms}^{-1}$ & $2.15 \mathrm{~ms}^{-1}$ & $2.75 \mathrm{~ms}^{-1}$ \\
\hline 1 & $\begin{array}{l}\text { Absorbed power in damper } \mathrm{C}_{4} \text { associated } \\
\text { with the thighs and pelvis in contact with } \\
\text { the seat }\end{array}$ & 1.20 & 2.04 & 6.67 \\
\hline 2 & $\begin{array}{l}\text { Absorbed power in damper } \mathrm{C}_{3} \text { associated } \\
\text { with the lower torso in contact with thighs } \\
\text { and pelvis }\end{array}$ & 2.90 & 3.78 & 10.31 \\
\hline 3 & $\begin{array}{l}\text { Absorbed power in damper } C_{2} \text { associated } \\
\text { with the upper torso in contact with the } \\
\text { lower torso. }\end{array}$ & 19.78 & 24.69 & 57.93 \\
\hline 4 & $\begin{array}{l}\text { Absorbed power in damper } \mathrm{C}_{1} \text { associated } \\
\text { with the head }\end{array}$ & 3.03 & 3.73 & 5.70 \\
\hline 5 & Total absorbed power & 26.91 & 34.24 & 80.61 \\
\hline
\end{tabular}

The vibration energy absorbed by different body segments and total absorbed power was calculated using the equation (12)-(13).

Table 3. Vibration energy absorbed by the body during work of the aggregate at various working speeds

\section{DISCUSSION}

Very little energy is absorbed in damper 1 associated with the head. while most of the absorbed power occurs in damper 2 , associated with the upper torso in contact with the lower torso.

The maximum amplitude the total absorbed power during the work of the aggregate with working speeds $2.75 \mathrm{~ms}^{-1}$ was $423 \mathrm{~W}$. Total absorbed power most often reached value of about $100 \mathrm{~W}$. Xie [11] studied the response of a 4-DOF human model to forced vibration originating from a vehicle (urban bus) traveling over an obstacle. In this case, the maximum amplitude total absorbed power was $36 \mathrm{~W}$. 


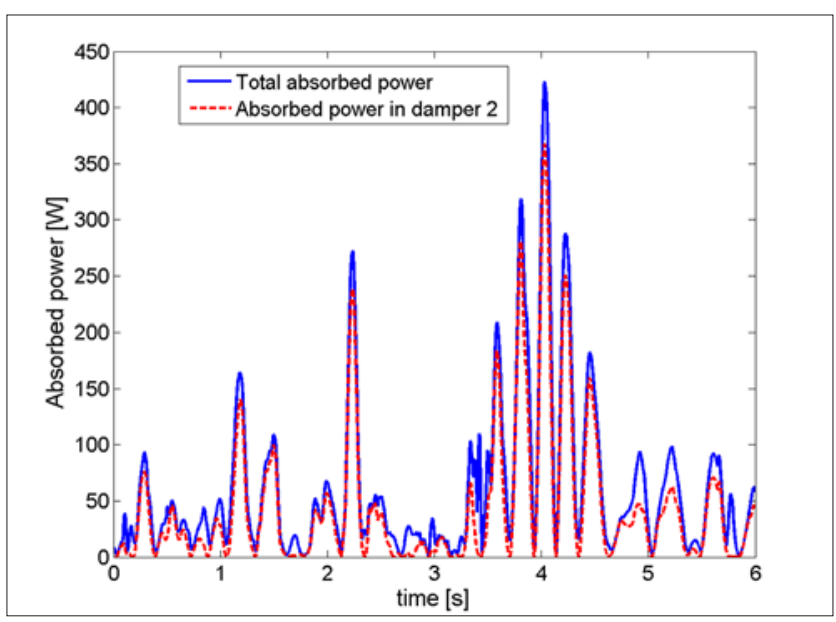

Figure 3. Total absorbed power and absorbed power in damper associated with the upper torso in contact with the lower torso during work of the aggregate with working speeds $2.75 \mathrm{~ms}^{-1}$

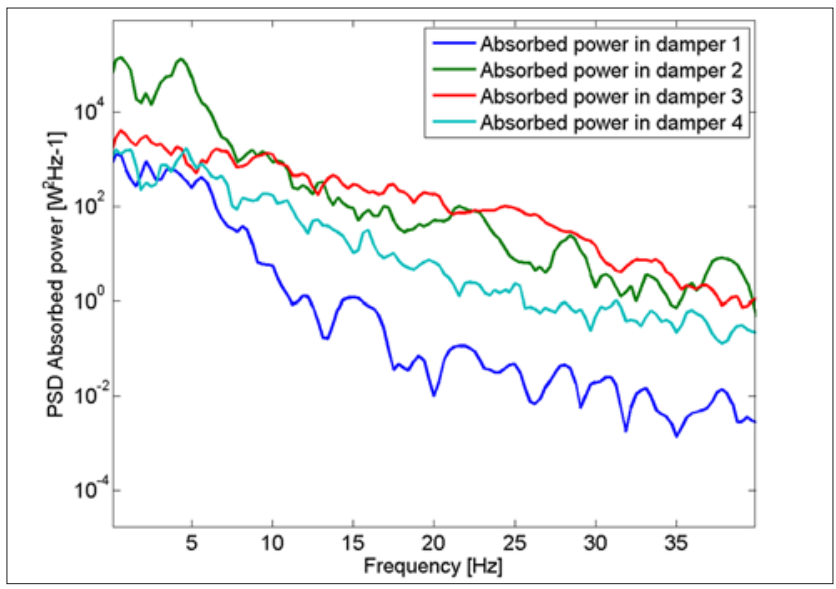

Figure 4. 4-DOF biodynamic model. Power spectral density (PSD) of absorbed power in various dampers during work of the aggregate with working speeds $2.75 \mathrm{~ms}^{-1}$

As can be seen from the spectra, the biggest power absorption occurred in the low-frequency band. In the frequency range $0.1-7.8 \mathrm{~Hz}$, most of the absorbed power occurred in the damper associated with the upper torso in contact with the lower torso. In the frequency range $10.0-$ $35.5 \mathrm{~Hz}$, most of the absorbed power occurred in the damper associated with the lower torso in contact with thighs and pelvis.

\section{CONCLUSIONS}

The concept of absorbed power as a measurement for evaluation of WBV exposure opens a new area for research. The important characteristic of absorbed power is that it has physical significance, and therefore can be measured as well as computed analytically. Power is a scalar quantity and can be summed-up in complex multi-degree of freedom systems to determine human response. A structural model of the human operator allows determination of the dynamic characteristics of the model, and study of the energy flow between the elements of the model, based on the real exciting forces from experimental research in field condition.
The vibration energy absorbed by the operators body is increased by increasing the driving speed of the agricultural combination.

In the analyzed 4-DOF biodynamic model, very little energy was absorbed in the damper associated with the head, while most of the absorbed power (more than 70\%) occurred in damper associated with the upper torso in contact with the lower torso.

In the future, the energy absorbed by the operator can become an indicator of the vibration level acceptable in this place of human work. A useful way to compare this concept with other measurements of vibration exposure in relation to health effects, would be to conduct epidemiological studies on different categories of professional drivers.

\section{Acknowledgement}

This study was supported by National Science Centre Research Project No. N N313 789040.

\section{REFERENCES}

1. Cieślikowski B. Modelling of the vibration damping in an operator's seat system. TEKA Kom Mot Energ Roln. OL PAN. 2009; 9: 24-31.

2. Juliszewski T. Badania zmienności drgań mechanicznych siodeł i poziomu dźwięku jako ergonomicznych parametrów ciągników rolniczych. (The variability in mechanical vibrations of seats and in noise levels as ergonomic parameters of farm tractors). Zeszyty Naukowe Akademii Rolniczej w Krakowie. Rozprawy nr 197. 1995.

3. ISO 5982 (1981): Vibration and shock - mechanical driving point impedance of the human body.

4. Liang CC, Chiang CF. A study on biodynamic models of seated human subjects exposed to vertical vibration. Int J Ind Ergon. 2006; 36: 869890 .

5. Wael Abbas, Ossama B, Abouelatta. Magdy S, El-Azab. Adel A, Megahed. Application of Genetic Algorithms to the Optimal Design of Vehicle's Driver-Seat Suspension Model. Proceedings of the World Congress on Engineering (London. U.K.. June 30 - July 2. 2010).2010; p 1630-1635.

6. Szczepaniak J, Kromulski J. Analysis of energy flow model in the biomechanical system human operator - agricultural combination. J Res Appl Agric Eng. 2011; 56(4): 138-142.

7. Szczepaniak J, Tanaś W, Pawłowski T, Kromulski J. Modeling of agricultural combination driver behaviour in aspect of safety of movement. Ann Agric Environ Med. 2014; 21(2): 403-406.

8. Szczepaniak J, Kromulski J, Dudziak B. Dynamic loads acting on the farm tractor operator at work in the field with the increased operating speed. Combustion Engines. 2013; 154(3): 981-984.

9. Lundström R, Homlund P. Absorption of energy during whole-body vibration exposure. J Sound Vib. 1998; 215(4): 789-799.

10. Szczepaniak J, Tanaś W, Kromulski J. Vibration energy absorption in the hole-body system of tractor operator. Ann Agric Environ Med. 2014; 21(2): 399-402.

11. Xie X. Absorbed power as a measure of whole body vehicular vibration exposure. Department of Mechanical Engineering. Concordia University Montreal. Quebec. Canada. 2001.

12. Nawayseh N, Griffin MJ. Power absorbed during whole-body vertical vibration: Effects of sitting posture. backrest. and foot rest. J Sound Vib. 2010; 329: 2928-2938

13. Tajanowskij G, Tanas W. The analysis of regular wheel loadings distribution at a statically unstable running system if an agricultural machine on rough surface. Teka commission of motorization and power industry in agriculture. 2010; Polish Academy of sciences branch in Lublin. Vol. X. 464-474

14. Rakheja S, Mandapuram S, Dong RG. Energy Absorption of Seated Occupants Exposed to Horizontal Vibration and Role of Back Support Condition. Industrial Health. 2008; 550-566.

15. ISO 2631-1. 1997. Mechanical Vibration and Shock e Evaluation of Human Exposure to Whole Body Vibration. Part 1: General Requirements. International Standards Organization. Switzerland.

16. Woodhouse. J. Linear damping models for structural vibration. J Sound Vib. 1998; 215(3): 547-569. 